\title{
Outreach and Community Engagement Activities to Complement Engineering Program Outcomes in Indian Context
}

\author{
Surendra Bandi ${ }^{1}$ \\ ${ }^{1}$ Department of Computer Science \& Engineering (CSE), Hyderabad Institute of Technology and Management (HITAM), \\ Hyderabad-India \\ ${ }^{1}$ surendra.mca@hitam.org
}

\begin{abstract}
:
Under Graduate Curriculum for engineering programs in India has been designed to emphasise deeper engagement of students with technical academic rigor to become strong at basic engineering principles, problem analysis, problem solving and develop engineering solution to a given well defined context of engineering. With the rapid change in the technical advancement front, the engineering needs of the people also have changed drastically and the existing model of imparting engineering education is becoming obsolete gradually. The accreditation agencies have come up with the set of attributes that are expected from engineering graduates to be professionally qualified to work on engineering problems. Engineering academic institutions in India started to make changes in their curriculum to fulfil the quality benchmarks of accreditations. The objective is to justify the attainment of all program outcomes specified within the four years of engineering under graduate program. This becomes a challenge when only pure academic courses are included in the curriculum. The graduates come out with the lower level skills like remembering and understanding but not the higher order skills like analysing, evaluating and creating engineering prototypes and products. A typical engineering curriculum in India allows students to experience limited creativity in terms of doing projects which are directly associated with contemporary engineering issues. Due to the nature of uncertainty and ill structured problems anticipated in future, academicians are encouraged to design curriculum by incorporating more generic content for learning and enable them to apply for specific context. All these are still carried out with well pre-formulated problems. There is a need to have students exposed to the live problems and contexts. This is only possible by including outreach and community engagement activities in design, delivery and assessment of engineering courses. These activities complement learning of technical aspects
\end{abstract}

and lead to better attainment of program outcomes. This paper brings out the impact of outreach activities as a work in progress initiatives at Hyderabad Institute of Technology and Management(HITAM), an engineering college based in Hyderabad, India.

Keywords: Outreach, Community Engagement, Curriculum, Program outcome

\section{INTRODUCTION}

India is all set to compete with developed nations in terms of engineering knowledge and skill capital.(Mohanty and Dash 2016) With the advantage of globalization and liberalization of international knowledge exchange initiatives, being a developing nation India is attempting to transform the way engineering education is offered. Initiatives at national level helping the institutions across the country to implement strategies to prepare the Indian engineering graduates to be on par with the trend setters of the top engineering performing countries. Technology has become an essential element of current society (Vennix, den Brok, and Taconis 2018). When there was a minimal need of engineering efforts for industry and society, expectation from the engineering graduates was to get sufficient training during the probation period and continue to take the same service throughout their career. But now a days, the technologies becoming obsolete in less time and the engineers require to learn continuously during their career as well. Therefore the accreditation agencies of engineering programs have come up with the list of essential technical and professional attributes that an engineer must acquire during the four years. The list include Engineering knowledge, Problem analysis, Design/development of solutions, Conduct investigations of complex problems, Modern tool usage, The engineer and society, Environment and sustainability, Ethics, Individual 
\& team work, Communication, Project management \& finance and Life-long learning. The list covers both technical and professional competencies. It not generally possible to accomplish all the attributes with the engineering curriculum offered in most of the Indian engineering institutions. It is necessary to design the courses ensuring the experiences to acquire engineering graduate attributes. Flexibility in the structure of the engineering programs allow faculty to add content which lead to maximum attainment of the program outcomes.

\section{METHODOLGOY}

HITAM(Hyderabad Institute of Technology and Management) is currently an affiliated college offering four engineering programs. Syllabus to the college is set by the affiliating university. The college has the vision of nurturing students with competencies to become confident about their careers and contribute to society. The college is planning to become autonomous soon. In the journey of getting autonomy, HITAM is building processes and initiatives to incorporate service learning courses effectively to fulfil the accreditation requirements while realizing the institution's vision. We have chosen the initiatives UBA(Unnat Bharat Abhiyan), EWB(Engineers Without Borders), EPICS(Engineering Projects in Community Service), Toastmasters, Technical Clubs with Emerging Technologies and memorandums of understanding with nongovernmental organizations who work for social cause. Though the curriculum designing is not within the control of college, there is scope for choosing relevant pedagogy to effectively deliver and add lot of social activities beyond the curriculum.

\section{A. UBA (UNNAT BHARAT ABHIYAN)}

Unnat Bharat Abhiyan is an Indian central government initiative to involve engineering students to adopt the villages and work with the rural community to understand the areas like village sanitation, drinking water supply, energy including renewable energy, agriculture and allied activities, irrigation, improving the technology of handicrafts and artisans, affordable housing, improving educational standards, Improving health and proper use of IT applications (Unnat Bharat Abhiyan, 2019). HITAM adopted five villages and involved students in collecting data of the villages to have projects from the direct clients. This enabled the first, second and third year students to have scope of thinking a project early in their program. Engineer and society, communication and lifelong learning are the skills which are certainly possible to acquire in this initiative.

\section{B. EWB(ENGINEERS WITHOUT BORDERS)}

EWB-India has been established as a non profit organization which involves engineers in sustainable rural development. EWB promotes responsible use of technology. Students of HITAM have started a student chapter of EWB-
India and learning leadership skills and technical skills which is a boost to the regular academics in engineering. (EWB-India). The initiatve has the scope of strong mapping with life long learning, project management and finance, teamwork, ethics and environment.

\section{EPICS(Engineering Projects in Community Service)}

This is an initiative of Purdue University, USA to have students partner with local society and work to address their needs using the engineering skill and knowledge learnt during the engineering program. Academic credit is given to the learning but not the service though the courses fall under service learning. HITAM adapted the framework of EPICS with the help of IUCEE(Indo Universal Collaboration of Engineering Education) and started complementing regular academic courses. All the first year students are introduced to EPICS with an orientation of the framework. Students are free to move out at any stage of the program. There is a filtering process to continue in EPICS when they enter into second year. Students who are asked to give a proposal including the experiences of community visit, outcomes of design thinking tasks and the action plan for addressing one of the shortlisted issues of the community. Proposals are reviewed and the suitable candidates are given opportunity to continue with EPICS. Wild entry for second, third and fourth year students at any stage is also permitted based on the context and the match of the need and skill. (EPICS at Purdue). This is one of the strongest initiative to capture majority of the technicla and professonal outcomes.

\section{TOASTMASTERS}

This is an organization which helps students to become leaders. HITAM has charted its toastmasters club during 2018 and several students started following the systematic approach of converting themselves into leaders. Students participate in fortnight meetings to practice and assess themselves in language, etiquette and gestures. They also have networked with many industry experts. (Toastmasters International). This brings communication, teamwork and lifelong skills amongst the students

\section{E. Technical Clubs with Emerging Technologies}

As there is significant gap between the curriculum taught and the demand of the recruiting industry, HITAM initiated technical clubs in emerging technologies like Internet of Things, Artificial Intelligence and Robotics. Students are recruited by conducting a written test and interview into the respective clubs which are targeted to become centres for excellence. Resource persons in the respective technologies deliver the course in blended mode. The course is run beyond the curriculum and beyond the regular working hours. Four days a week is sufficient to run the curriculum of the affiliating university and the rest of the two days are used for these activities. 
F. Memorandums of understanding with nongovernmental organizations

HITAM signed Memorandum of understanding with Palle Srujna, an NGO which brings out grassroots innovations of the rural India and share with rest of the nation to bring recognition and meaningful application of the inventions. Students participate in Chinna Shodha Yatra (CSY), a walk in search of knowledge in villages organized by Palle Srujana. Internships to the suitable students are also provided by this organization. This helps the students to understand the engineering principles involved in the inventions and can document the details of the innovation. Exhibition of innovations by rural inventors is organized in the campus to trigger passion among the engineering students to think about engineering behind simple but powerful innovations by the rural community (Palle Srujana).

\section{RESULTS}

Outcome of the Outreach and Community Engagement at HITAM have been successful in terms of enhanced student learning and contributing to address more attainment of engineering program outcomes. EPICS was introduced in 2016 and more than 300 students have experienced the framework and succeeded in their academics and getting meaningful employment. Students who have graduated two years ago have appreciated the program as still the impact is there on them during their careers. UBA at HITAM has successfully completed one year and covered the survey of five adopted villages. Students also have come up with six projects proposals out of the problems identified during their village visits. They also have learnt different tools of social engagement and data collection techniques. This further empowered them to formulate engineering problems out of the discussions with the clients. More than 200 students and ten faculty have been part of the initiative. There are 12 students as HITAM Toastmasters to graduate and found successful careers. Current strength of the club is 21 and there is an impact of toastmasters on more than 20 other people. Toastmasters at HITAM have become the source of talent for running the college magazine and offer services for all the official stage events on campus. 20 students have become part EWB-India-HITAM Student chapter and one two faculty are involved in the same. The 20 students have started organizing their work beyond college hours over virtual environment and working on the project planning. There are about 300 more students involved in the technical clubs and social initiatives.

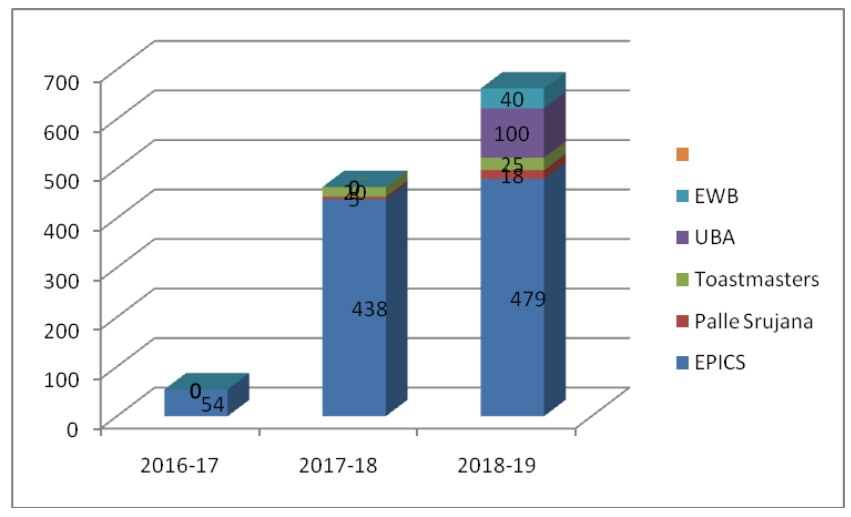

Figure 1: Increased enrollment into Outreach Initiatives

\section{DISCUSSION}

Outreach Initiatives beyond curriculum at HITAM have picked momentum to create enthusiasm among the students and helping them to learn better. Not all the students have similar academic and non academic passions to take forward. Variety of community engagement and outreach activities allow the student to be part of any of the initiatives and improve their understanding. This also brings practice of engineering integrated in the four years of undergraduate engineering. As part of continuous improvement of quality of engineering courses, outreach and community engagement can be directly included in the courses or delivery methodologies. Usually students, faculty and parents think the outreach activities do not add much value as these are not given any academic credit an involve a bit of risk element as the student might require to physically travel during the academic schedule. Hence there is a need to include the service learning courses in the curriculum itself. It is always recommended to work collaboratively with nongovernmental organizations to ensure honesty and ethical perspective of the initiatives taken up for society.

\section{Conclusions}

It is clear that integrating outreach and community engagement complements the learning of students in more meaningful way. Scope of addressing more program outcomes is witnessed in the community engagement activities. Even the attention span of students has been decreased to the least these days. Therefore there is a quick need of incorporating outreach and community engagement courses in the curriculum itself instead of treating those as extracurricular activities. Wide range of choices have to be given to the students to choose among multiple options and combinations to complete their engineering program within four years. The more generic students get the more confused if the programs are offered to be ambitious. It is advised to keep the courses as short as possible and create scope for self thinking and problem solving skills. The 
figure 1 indicates the increased interest of students for enrolment into the outreach activities.

\section{Acknowledgement}

Motivation for these kind of studies for transformations in engineering education have been triggered with support of IUCEE(Indo Universal Collaboration for Engineering Education). I thank Dr. Krishna Vedula for his continuous efforts in encouraging us patiently to showcase our experiences on various international platforms and connecting us with eminent leaders in engineering education. I extend my sincere thanks to the chairman of our college (HITAM) Mr. Prashanth Arutla for his unstoppable passion to be fundamentally different in providing education that makes the students as confident individuals and contribute to society. It is also time to thank our Outreach team at HITAM Mrs. Hema Mahajan, Mr. Santosh Naik, Mr. Yakub, Mr. Ali, Mrs. Anita Kumari and Mr. Kannaiah. Efforts of our students who have been active throughout the implementation of initiatives are also worth acknowledging at this point of time.

\section{References}

Mohanty, Atasi and Deepshikha Dash. 2016. "Engineering Education in India: Preparation of Professional Engineering Educators." Journal of Human Resource and Sustainability Studies 04(02):92-101.

Vennix, Johanna, Perry den Brok, and Ruurd Taconis. 2018. "Do Outreach Activities in Secondary STEM Education Motivate Students and Improve Their Attitudes towards STEM?" International Journal of Science Education 40(11):1263-83.

EPICS at Purdue. (n.d.). Retrieved September 22, 2019, from https://engineering.purdue.edu/EPICS: https://engineering.purdue.edu/EPICS

EWB-India. (n.d.). Retrieved September 22, 2019, from https://www.ewb-india.org/about-us/: https://www.ewbindia.org/about-us/

Palle Srujana. (n.d.). Retrieved September 22, 2019, from https://www.toastmasters.org/: https://www.toastmasters.org/

Toastmasters International. (n.d.). Retrieved September 22, 2019, from https://www.toastmasters.org/: https://www.toastmasters.org/

Unnat Bharat Abhiyan. (2019, January 01). Retrieved September 22, 2015, from www.unnatbharatabhiyan.gov.in: http://unnatbharatabhiyan.gov.in/app/webroot/files/circular $\mathrm{s}$ 